\title{
O PACIENTE NO SISTEMA CENTRO CIRÚRGICO - UM ESTUDO SOBRE PERCEPÇÕES E OPINIÕES DE PACIENTES EM RELAÇĀO AỎ PERIODO TRANSOPERATÓRIO *
}

\section{Ana Irma Rodrigues**}

RODRIGUES, A. I. O paciente no sistema centro cinírgico - um estudo sobre percepçð̄es e opiniठ̌es de pacientes em relação ao período transoperatório. Rev. Esc. Enf. USP, São Paulo, 18(2):163-176, 1984.

A autora fez um estudo sobre as percepçōes e opiniōes do paciente, durante o periodo transoperatório, relacionadas ao ambiente físico e humano do sistema centro cirürico em três hospitais de Londrina.

\section{INTRODUÇÃO}

O sistema centro cirúrgico, reconhecidamente cada vez mais complexo, passa por acentuado desequilíbrio no dualismo tecnologia/humanismo. As atividades e tarefas da equipe cirúrgica, acompanhando a crescente complexidade do ato operatório, condiciona a pouca atenção que se vem dando ao relacionamento humano.

Autores como ARMSTRONG ${ }^{2}$ e OLSEN ${ }^{23}$ alertam para o fato de que as crescentes mudanças tecnológicas, levam a enfermeira do centro cirúrgico a questionar como essas mudanças estão influenciando a qualidade do cuidado de enfermagem necessário ou proporcionado.

RADINA ${ }^{25}$ refere-se à barreira constituída pela estrutura social e física do centro cirúrgico, e salienta a importância da equipe de enfermagem estar ciente das percepções do paciente, diante desse ambiente desconhecido.

NOLAN ${ }^{22}$ atribui à enfermeira de centro cirúrgico a tarefa de manter um ambiente seguro, tanto no aspecto físico como psíquico, e favorecer o envolvimento interpessoal da equipe cirúrgica na responsabilidade do atendimento às necessidades biopsicossocioespirituais do paciente.

São muitos os trabalhos que preconizam e/ou enfatizam a importância

- Resumo da Dissertação de Mestrado apresentada à Escola de Enfermagem da Universidade de São Paulo.

** Professor Assistente do Departamento de Enfermagem do Centro de Ciências da Saúde da Universidade Estadual de Londrina. 
da atuaçæ̃o da enfermeira, como membro profissional da equipe cirúrgica e como líder da equipe de enfermagem, em assegurar ao paciente, na fase transoperatória, assistência personalizada, contínua e integrada (BERRY \& MICHAEL $^{5}$; FAY ${ }^{13}$; FEHLAU ${ }^{14}$; PANZA $^{24}$ ).

Considere-se a atual concepção de estrutura e de funcionamento hospitalar fundamentados na análise de sistemas, contida em trabalhos de ANGERAMI $^{1}$; CASTELLANOS et alii $^{8}$; CHAVES ${ }^{9}$; JOUCLAS ${ }^{16}$; LAUFMAN $^{18}$. O sistema centro cirúrgico recebe o paciente, "input", com sua demanda de necessidades afetadas, para um processo que compreende todas as açðes a serem desenvolvidas na fase transoperatória; o paciente operado será o "output", capaz de proporcionar informaçóes a respeito do processo, daí obtendo-se condições para a retroalimentação do sistema. Efetivamente, posicionado o paciente como fonte informante, $a(0)$ enfermeira(o) do centro cirúrgico poderá prevenir situaçðes por ela(e) consideradas como traumatizantes, física e psicologicamente, bem como prover as condiçðes positivas, resultantes de sua percepção no contexto ambiental.

Com esses propósitos foram determinados os objetivos deste trabalho:

1) identificar os problemas sentidos pelos pacientes na sua interação como contexto (físico e humano) do centro cirúrgico, durante o período transoperatório;

2) verificar a presença e atuação da enfermagem no periodo transoperatório, tal como percebida ou reconhecida pelo paciente cirúrgico;

3) identificar, no contex to centro cinúrgico, os fatores que afetaram, de maneira agradável ou desagradável, as percepç̃es do paciente durante o período transoperatório

\section{MATERIAL E MÉTODO}

$O$ estudo foi realizado em três hospitais gerais da cidade de Londrina, um oficial e dois particulares, referidos respectivamente como A, B e C.

A população foi constiturda de pacientes de ambos os sexos, submetidos a cirurgia realizada sob anestesia raquidiana ou peridural lombar.

Foram entrevistados 362 pacientes que preencheram os requisitos previamente determinados.

Para a coleta de dados, utilizou-se como instrumento um formulário constituído por um conjunto de questōes abrangendo identificação, dados referentes à cirurgia realizada, tipo de anestesia, medicação pré-anestésica, drogas sedativas, e 36 perguntas relativas a: interação do paciente com o contex to físico e humano do centro cirúrgico; presença e atuação da enfermagem no período transoperatorio, segundo a percepção do paciente; e fatores 
que constituem para o paciente, no centro cirúrgico, percepçōes agradáveis e percepções desagradáveis.

\section{RESULTADOS E DISCUSSÃO}

Os resultados obtidos foram apresentados em 53 tabelas, discutidos em quatro grupos interligados.

1) Características gerais da amostra.

2) Problemática na interação paciente-contexto sistema centro cirúrgico no periodo transoperatório.

3) Presença e atuação da enfermagem no período transoperatório, segundo a percepção do paciente.

4) Fatores que constituem para o paciente, no contexto ambiental do centro cirúrgico, percepçð̄es agradáveis e percepçðes desagradáveis.

$\mathrm{Na}$ caracterização da amostra observou-se que os pacientes, na maioria, $(66,58 \%)$ pertenciam à faixa etária de 20 a 39 anos de idade; eram do sexo feminino $(74,59 \%)$; casados $(87,57 \%)$.

Quanto à categoria sócio-econômica, 60,50\% contribuiam para o INAMPS; $26,80 \%$ eram indigentes e $12,70 \%$, particulares.

- Problemática na interação paciente-contexto sistema centro cirúrgico no periodo transoperatório.

É tarefa da enfermagem, postulada por LAMBERTSEN ${ }^{17}$, incentivar a participação do paciente no planejamento de sua assistência, considerando-o como um elemento da equipe e orientando-o adequadamente.

Conforme conceituam BARNETT ${ }^{3}$; CASTELLANOS ${ }^{7}$; De LAPPE $^{10}$; EPSTEIN $^{12}$; PANZA $^{24}$, quanto melhor o paciente entender a importáncia de sua cooperação e participação, melhores serão suas condiçð̃es para superar o estresse da doença e a própria cirurgia e anestesia. "Os pacientes têm o direito de receber informaçōes completas, que sirvam de base para que possam lidar com o sistema e não serem por ele abafados" (BELAND \& PASSOS ${ }^{4}$ ).

Os resultados mostram que, dos 362 pacientes, $174(48,07 \%)$ foram encaminhados ao centro cirúrgico sem nenhuma orientação prévia a respeito de sua condição de paciente cirúrgico.

Constata-se, pelas respostas dos pacientes, que a orientação para cirurgia, quando houve, foi feita de maneira assistematizada, por meio de palavras soltas ou conversaçoes fragmentadas, sendo eles deixados com muitas dúvidas sobre o que iria acontecer no trans e no pós-operatório.

PANZA $^{24}$ provou ser significativa a diminuição do estresse nos pacientes 
quando estes recebiam orientação, de acordo com os problemas identificados, na visita pré-operatória.

Além das informaçðes concernentes aos procedimentos terapêuticos, deve ser valorizado o relacionamento humano. MAHOMET $^{20}$ afirma que uma presença conhecida durante $o$ ato anestésico-cirúrgico representa, para o paciente, segurança física e psicológica. Procurou-se verificar se os pacientes entrevistados haviam reconhecido alguém no centro cirúrgico e, em particular, a enfermeira. Os resultados demonstraram que 188 pacientes $(51,93 \%)$ reconheceram um ou alguns dos elementos da equipe cirúrgica; $75,53 \%$ reconheceram o cirurgiăo; o anestesiologista foi mencionado, nos hospitais B e C por 17,03\% dos pacientes; somente no hospital A houve referência de $7(12,50 \%)$ pacientes a elementos da enfermagem.

Quanto a esses dados verificourse que a maior percentagem de pacientes que reconheceu alguém no centro cinúrgico pertencia ao grupo de pacientes orientados, o que nos leva a inferir que, quando os elementos da equipe cirúrgica entram em contato com os pacientes no pre-operatório, estes os reconhecem durante o periodo transoperatorio.

Nos três hospitais nota-se, pelos dados obtidos, que a(o) enfermeira(o) não realiza a visita pré-operatória "Todos acham a visita pré-operatória futil para a ascistência transoperatória mas ninguem a aplica. . . o contato da enfermeira do centro cirúrgico com o paciente, na fase prt-operatoria, praticamente ainda nżo existe" (WELSH \& RICHARDSON ${ }^{27}$ ).

RICHTER ${ }^{26}$ YANICK \& PODOBNIKAR abordam a necessidade de segurança do paciente en se sentir como pesean no centro cirargico, pelo respeito de todos os elementos da equipe a ma individualidade, que o cumprimentar e o tratar pelo nome.

No presente estudo, constatourse que, dos 362 pacientes, 53,04\% não foram cumprimentados e a 53,31\% ningeten perguntou o nome durante o periodo transoperatório.

Toda atividade da equipe e uma forma de interafio, que o paciente recebe $e$ interpreta de acordo com sula pexcepgio, durante o periodo transoperatório.

Pela anslise dos dados, verificourse que $59,52 \%$ dos pacientes identificaram o anestesiologista como o elemento da equipe que lhes dispensou mais atenção; a(o) enfermeira (0) foi citada(0) por apenas 5,06\% dos pacientes.

Neste trabalho constatou-se tambem que ha tipos de diflogo entre os elementos da equipe cirurgica que causam preocupagio a paciente durante o período transoperatório. A maior percentagem $(22,75 \%)$ refere-se a procedimentos técnicos da cinurgia; 18,18\% referen-se ds discussóes e reclamaçôs entre os membros da equipe cirúrgica. Verificou-se, ainda, que 45 pa 
cientes $(12,43 \%)$ referiram-se à irritação dos elementos da equipe cirúrgica. $\mathrm{O}$ elemento mais citado nos três hospitais foi o anestesiologista.

Todos os elementos em quem os pacientes perceberam irritaçăo foram identificados em sua categoria profissional ou função, tendo aqueles descrito o motivo da irritação que, direta ou indiretamente, os agrediu.

Durante o ato anestésico-cirúrgico, os pacientes apresentaram necessidades biopsicossociais que foram verbalizadas através de solicitaçoes aos membros da equipe cirúrgica (Tabela 1).

Tabela 1 - Distribuição dos pacientes cirúrgicos, em número e percentagem, por hospital de estudo, segundo o tipo de solicitação feita durante o período transoperatório.

\begin{tabular}{|c|c|c|c|c|c|c|c|c|}
\hline \multirow{2}{*}{$\begin{array}{l}\text { Tipo de solicitação } \\
\text { feita pelos pacientes }\end{array}$} & \multicolumn{2}{|c|}{$\mathbf{A}$} & \multicolumn{2}{|c|}{ B } & \multicolumn{2}{|c|}{ C } & \multicolumn{2}{|c|}{ Total } \\
\hline & No & $\%$ & No & $\%$ & No & $\%$ & No & $\%$ \\
\hline \multicolumn{9}{|l|}{ Area Técnica } \\
\hline $\begin{array}{l}\text { - Não dormir durante a cirurgia } \\
\text { - Fazer laqueadura de trompas } \\
\text { - Não ver o ato cirúrgico } \\
\text { - Aplicar mais anestésico } \\
\text { - Suspender a cirúrgia } \\
\text { - Controlar o soro que estava fora da veia } \\
\text { - Tirar um "calo" do pé }\end{array}$ & $\begin{array}{l}06 \\
10 \\
05 \\
03 \\
02 \\
02 \\
01\end{array}$ & $\begin{array}{r}9,38 \\
15,63 \\
7,81 \\
4,69 \\
3,12 \\
3,12 \\
1,56\end{array}$ & $\begin{array}{l}15 \\
- \\
\overline{0} \\
- \\
- \\
-\end{array}$ & $\begin{array}{l}68,18 \\
- \\
4,55 \\
= \\
-\end{array}$ & $\begin{array}{l}06 \\
\overline{01} \\
- \\
- \\
-\end{array}$ & $\begin{array}{l}54,55 \\
\overline{9}, 09 \\
- \\
- \\
-\end{array}$ & $\begin{array}{l}27 \\
10 \\
06 \\
04 \\
02 \\
02 \\
01\end{array}$ & $\begin{array}{r}27,84 \\
10,31 \\
6,19 \\
4,12 \\
2,06 \\
2,06 \\
1,03\end{array}$ \\
\hline Area Expressiva & & & & & & & & \\
\hline $\begin{array}{l}\text { - Molhar a boca } \\
\text { - Melhorar a posição dos braços e/ou do } \\
\text { corpo na mesa cirúrgica } \\
\text { - Zelar pela manutenção de sua vida } \\
\text { - Zelar peia segurança do feto } \\
\text { - Ser coberto } \\
\text { - Não ficar sozinho na sala de operaçōes } \\
\text { - Auxflio durante o vômito } \\
\text { - Retirar os campos cirúrgicos do rosto } \\
\text { do paciente }\end{array}$ & $\begin{array}{l}08 \\
04 \\
01 \\
03 \\
03 \\
03 \\
01\end{array}$ & $\begin{array}{r}12,50 \\
6,25 \\
1,56 \\
4,69 \\
4,69 \\
4,69 \\
1,56\end{array}$ & $\begin{array}{l}- \\
02 \\
\overline{03} \\
01 \\
- \\
-\end{array}$ & $\begin{array}{c}9,09 \\
- \\
13,63 \\
4,55 \\
- \\
- \\
-\end{array}$ & $\begin{array}{l}\overline{02} \\
01 \\
\overline{01} \\
- \\
-\end{array}$ & $\begin{array}{l}- \\
\overline{18,18} \\
9,09 \\
\overline{9,09} \\
- \\
-\end{array}$ & $\begin{array}{l}10 \\
06 \\
0.5 \\
04 \\
04 \\
03 \\
\\
\end{array}$ & $\begin{array}{r}10,31 \\
6,19 \\
5,16 \\
4,12 \\
4,12 \\
3,09\end{array}$ \\
\hline Total & 64 & 100,00 & 22 & 100,00 & 11 & 100,00 & 97 & 100,00 \\
\hline
\end{tabular}

A análise dos dados da tabela 1 possibilita verifiear que o maior número de solicitaçoes ocorreu no hospital A, feitas por $64(65,98 \%)$ pacientes, em relação à assistência de enfermagem, as solicitaçס̃es, em $54,69 \%$ dos casos, relacionam-se à área expressiva.

Importa ressaltar que, nos hospitais $\mathrm{B}$ e $\mathrm{C}$, a maior ocorrência de solieitações relaciona-se à área técnica, $(72,73 \%$ e $63,64 \%$ respectivamente). 
Os resultados mostram que, dos 7 pacientes que dirigiram a sua solicitação d̀(ao) enfermeia(o), 4 ño foram atendidos.

O paciente sofre durante a sua permanência no centro-cirúrgico uma série de procedimentos comuns a qualquer tipo de tratamento anestésico-cirúrgico, ou específico, e devem ser preparados, não só para o que o espera, como, também, para o que é esperado dele.

Conforme os resultados, dos 362 pacientes $(64,92 \%)$ não receberam nenhuma explicação sobre os cuidados prestados durante a cirurgia. Dos que receberam a explicaçđo, $65,36 \%$ identificaram o anestesiologista como a pessoa que transmitiu a explicação. Quanto aos elementos da enfermagem, a(o) enfermeira(o) e a circulante da sala foram identificadas por 4 pacientes $(3,15 \%)$.

$\mathrm{Na}$ interaçăo equipe cirúrgica-paciente-ambiente, $161(44,48 \%)$ pacientes manifestaram sua preocupação e ansiedade, pela reação de choro (Tabela 2).

Tabela 2 - Distribuição dos pacientes em número e porcentagem, por hospital de estudo, segundo as causas do choro durante o período transoperatório.

\begin{tabular}{|c|c|c|c|c|c|c|c|c|}
\hline \multirow[b]{2}{*}{ Causas de choro } & \multicolumn{2}{|r|}{$\mathbf{A}$} & \multicolumn{2}{|r|}{ B } & \multicolumn{2}{|r|}{ C } & \multicolumn{2}{|c|}{ Total } \\
\hline & No & $\%$ & Nọ & $\%$ & Nọ & $\%$ & Nọ & $\%$ \\
\hline Medo da morte & 26 & 35,14 & 24 & 43,64 & 08 & 25,00 & 58 & 36,03 \\
\hline Sensação de abandono & 17 & 22,97 & 09 & 16,36 & 10 & 31,25 & 36 & 22,36 \\
\hline Medo das conseqüências da anestesia & 13 & 17,57 & 07 & 12,73 & 08 & 25,00 & 28 & 17,39 \\
\hline Emoção ao ouvir o choro do recém-nascido & 02 & 2,70 & 12 & 21,81 & 05 & 15,63 & 19 & 11,80 \\
\hline Dor durante a cirurgia & 06 & 8,11 & 01 & 1,82 & 01 & 3,12 & 08 & 4,97 \\
\hline Tipo de relacionamento com o paciente & 05 & 6,76 & 01 & 1,82 & - & - & 06 & 3,73 \\
\hline Não conhecimento do cirurgião & 03 & 4,05 & - & - & - & - & 03 & 1,86 \\
\hline Amputação do membro inferior & 02 & 2,70 & 01 & 1,82 & - & - & 03 & 1,86 \\
\hline Total & 74 & 0,00 & 55 & 00,00 & 32 & 1000 & 161 & 00,00 \\
\hline
\end{tabular}

A análise dos dados da tabela 2 possibilita verificar que, em relação ao total de pacientes, $36,03 \%$ citaram como causa de choro o medo da morte, $22,36 \%$ citaram a sensação de abandono e $17,39 \%$ citaram o medo das conseqüências da anestesia. Observa-se, também, que no hospital B, dos 55 pacientes, $12(21,81 \%)$ citaram como causa de choro a emoção ao ouvir o choro do recém-nascido.

Para BRUNNER et alii ${ }^{6}$, DUGAS $^{11}$ e GRAHAN \& CONLEY ${ }^{15}$, o choro é uma resposta emocional que, geralmente, denota sentimentos de impotência do paceinte para manejar seus problemas.

Acreditamos, pois, que assistir o paciente, através da identificação e aten- 
dimento de reais necessidades deste, é a razão fundamental da presença da(o) enfermeira(o) no período transoperatório, no desempenho de seu papel expressivo, em que ela ouve, observa e esclarece o paciente, quanto aos problemas sentidos e reduz as tensð̃es.

- Presença e atuação da enfermagem no periodo transoperatório, segundo a percepção do paciente.

McPHAIL ${ }^{19}$ atribui à enfermeira a responsabilidade, no momento da recepção do paciente no centro cirúrgico, iniciar interação positiva que desperte, no paciente, confiança nas açôes da equipe cirúrgica.

Verificou-se que, nos três hospitais, $75,42 \%$ dos pacientes não identificaram os elementos da equipe cirúrgica que os receberam; $15,75 \%$ mencionaram a $(0)$ enfermeira(o).

BELAND e PASSOS ${ }^{4}$ opinam que o significado do contato físico, no estabelecimento de relação de auxílio com uma pessoa fisicamente doente, vem da associação entre relacionamento espacial e interpessoal.

A equipe cirúrgica ocupa o "espaço íntimo" para atender às necessidades psicobiológicas dos pacientes na fase transoperatória.

Neste estudo obteve-se, como mostram os dados da Tabela 3, a informação de que o contato físico dos elementos da equipe cirúrgica, no atendimento às necessidades básicas, seja na área expressiva, seja na área técnica, tem para o paciente o significado de gesto afetuoso. Apesar desses contatos físicos caracterizarem açס̄es de enfermagem, na prestação de cuidados durante 0 ato anestésico-cirúrgico, e de serem valorizados pelos pacientes, a ponto destes interpretá-los como gestos de carinho, $51,04 \%$ dos pacientes ñ̃o identificaram o elemento da equipe cirúrgica envolvido nesse relacionamento. A participação da enfermagem foi identificada somente por $8,85 \%$ dos pacientes. 
Tabela 3 - Distribuição dos pacientes, em número e percentagem, por hospital de estudo, segundo a relação de gestos afetuosos que receberam durante o período transoperatório.

\begin{tabular}{|c|c|c|c|c|c|c|c|c|}
\hline \multirow[b]{2}{*}{ Gestos afetuosos } & \multicolumn{2}{|r|}{$\mathbf{A}$} & \multicolumn{2}{|r|}{ B } & \multicolumn{2}{|c|}{ C } & \multicolumn{2}{|c|}{ Total } \\
\hline & No & $\%$ & No & $\%$ & Nọ & $\%$ & Nọ & $\%$ \\
\hline $\begin{array}{l}\text { - Acariciar a testa ou o rosto do pa- } \\
\text { ciente } \\
\text { - Segurar os ombros e a cabeça do pa- } \\
\text { ciente durante a aplicação do anes- } \\
\text { tésico } \\
\text { - Massagear os braços do paciente de- } \\
\text { vido a "formigamento" } \\
\text { - Dar "tapinhas" nos ombros do pacien- } \\
\text { te } \\
\text { - Colocar os ombros e os braços do } \\
\text { paciente em posição correta, na mesa } \\
\text { cirúrgica } \\
\text { - Prender os cabelos do paciente com } \\
\text { a touca } \\
\text { - Ajudar o paciente a passar da maca } \\
\text { para a mesa cirúrgica e cobrí-lo } \\
\text { - Limpar o suor do rosto do paciente } \\
\text { - Amparar a cabeça do paciente e lim- } \\
\text { par-lhe a boca aposo vómito } \\
\text { - Enxugar as lágrimas do paciente }\end{array}$ & $\begin{array}{l}10 \\
02 \\
03 \\
02 \\
02 \\
01\end{array}$ & $\begin{array}{r}10,75 \\
20,43 \\
3,23 \\
10,75 \\
2,15 \\
3,23 \\
2,15 \\
2,15 \\
1,08\end{array}$ & $\begin{array}{l}01 \\
04 \\
02 \\
- \\
- \\
-\end{array}$ & $\begin{array}{r}24,20 \\
17,74 \\
12,90\end{array}$ & $\begin{array}{l}- \\
- \\
-\end{array}$ & $\begin{array}{l}35,13 \\
16,21 \\
21,62\end{array}$ & $\begin{array}{l}05 \\
02 \\
02 \\
01\end{array}$ & $\begin{array}{l}2,61 \\
1,04 \\
\\
1,04 \\
0,51\end{array}$ \\
\hline Total & 93 & 100,00 & 62 & 100,00 & 37 & 100,00 & 1921 & 100,00 \\
\hline
\end{tabular}

$(\bullet)$ C Cuidados de enfermagem interpretados pelos pacientes como gestos afetuosos.

$(-)=$ Gestos afetuosos

A análise da tabela 3 possibilita verificar que $104(54,17 \%$ pacientes, nos três hospitais, interpretaram cuidados de enfermagem como sendo gestos afetuosos.

Nota-se que, nos trés hospitais, a maior percentagem $(35,94 \%)$ dos pacientes informou que o gesto afetuoso recebido foi o de acariciar a testa ou o rosto.

Dos 362 pacientes, $173(47,79 \%)$ sentiram desconforto físico durante a cirurgia. Dos 125 pacientes que se queixaram a alguém, 52,00\% o fizeram ao anestesiologista; $42,40 \%$ nao identificaram o elemento da equipe a quem se dirigiram e apenas $4(30,20 \%)$ identificaram a(o) enfermeira(o) como sendo a pessoa a quem recorreram.

Os resultados deste trabalho demonstram que os pacientes percebem a necessidade de assistência que proporcione segurança fúsica e emocional; e que esta assistência envolve não somente as açðes e atitudes de enfermagem, como também as correspondentes aos demais elementos da equipe cirúrgica (Tabelas 4 e 5). 
Tabela 4 - Distribuição dos pacientes cirúrgicos, em número e porcentagem, por hospital de estudo, segundo o tipo de descoforto físico sentido durante a cirurgia.

\begin{tabular}{|c|c|c|c|c|c|c|c|c|}
\hline \multirow[b]{2}{*}{ Tipos de desconforto físico } & \multicolumn{2}{|c|}{$\mathbf{A}$} & \multicolumn{2}{|r|}{ B } & \multicolumn{2}{|r|}{$\mathbf{C}$} & \multicolumn{2}{|c|}{ Total } \\
\hline & No & $\%$ & Nọ & $\%$ & No & $\%$ & Nọ & $\%$ \\
\hline $\begin{array}{l}\text { Cansaço e/ou dor - "posição descon- } \\
\text { fortável na mesa cirúrgica" } \\
\text { Dor e/ou "formigamento" nos membros } \\
\text { superiores } \\
\text { Dor e desconforto durante a punção } \\
\text { lombar para a anestesia } \\
\text { Dispnéia - "sensação de morte" } \\
\text { Dor durante a cirurgia } \\
\text { Náuseas e/ou vômitos } \\
\text { Frio } \\
\text { Dor no pescoço } \\
\text { Dispnéia - "Campos cinúrgicos sobre } \\
\text { o rosto" } \\
\text { Cefaléia e/ou compressáo sobre os olhos } \\
\text { Calor }\end{array}$ & $\begin{array}{l}08 \\
20 \\
14 \\
08 \\
05 \\
05 \\
05 \\
\\
\\
06 \\
02 \\
01\end{array}$ & $\begin{array}{r}7,02 \\
17,54 \\
12,28 \\
7,02 \\
4,39 \\
4,39 \\
\\
5,26 \\
1,75 \\
0,87\end{array}$ & $\begin{array}{l}11 \\
\overline{01} \\
01 \\
02 \\
01 \\
-\overline{01} \\
-\end{array}$ & $\begin{array}{c}31,43 \\
- \\
2,86 \\
2,86 \\
5,71 \\
2,86 \\
- \\
2,86\end{array}$ & $\begin{array}{l}05 \\
02 \\
- \\
01 \\
01 \\
- \\
- \\
- \\
-\end{array}$ & $\begin{array}{c}20,83 \\
8,33 \\
- \\
4,17 \\
4,17 \\
- \\
- \\
- \\
-\end{array}$ & $\begin{array}{l}24 \\
22 \\
15 \\
10 \\
08 \\
06 \\
\\
06 \\
03 \\
01\end{array}$ & $\begin{array}{r}13,87 \\
12,72 \\
8,67 \\
5,78 \\
4,62 \\
3,47 \\
\\
3,47 \\
1,73 \\
0,58\end{array}$ \\
\hline Total & 114 & 100,00 & 35 & 100,00 & 24 & 100,00 & 18 & 100,00 \\
\hline
\end{tabular}

A análise dos dados da tabela 4 possibilita verificar que os tipos de desconforto físico mais citados pelos 173 pacientes foram: cansaço e/ou dor devido a posiçâo desconfortável na mesa cirúrgica (26,59\%); dor e "formigamento" nos membros superiores $(18,50 \%)$; dor e desconforto durante o punção lombar $(13,87 \%)$.

Destaca-se ainda que dos 114 pacientes do hospital A, 20 (17,54\%) referiram-se a Dispnéia tipo "sensação de morte". 
Tabela 5 - Distribuição dos pacientes em número e percentagem, por hospital de estudo, segundo as causas de insatisfação com a assistência recebida durante o período transoperatório.

\begin{tabular}{|c|c|c|c|c|c|c|c|c|}
\hline \multirow[b]{2}{*}{ Causas de insatisfação } & \multicolumn{2}{|c|}{$\mathbf{A}$} & \multicolumn{2}{|r|}{ B } & \multicolumn{2}{|r|}{ C } & \multicolumn{2}{|c|}{ Total } \\
\hline & No & $\%$ & No & $\%$ & Nọ & $\%$ & No & $\%$ \\
\hline $\begin{array}{l}\text { Desatenção para com o paciente } \\
\text { Desorganização no atendimento } \\
\text { Atitudes agressivas para com o paciente } \\
\text { Fala insistente e voz irritante } \\
\text { Inabilidade técnica na punção lombar } \\
\text { Brincadeiras e/ou piadas } \\
\text { Inabilidade técnica na punção venosa } \\
\text { Insegurança na execução dos procedi- } \\
\text { mentos de enfermagem }\end{array}$ & $\begin{array}{l}38 \\
07 \\
09 \\
- \\
08 \\
03 \\
04 \\
01\end{array}$ & $\begin{array}{r}54,28 \\
10,00 \\
12,86 \\
- \\
11,43 \\
4,29 \\
5,71 \\
1,43\end{array}$ & $\begin{array}{l}12 \\
04 \\
- \\
- \\
\overline{03} \\
01 \\
-\end{array}$ & $\begin{array}{c}60,00 \\
20,00 \\
- \\
- \\
\overline{15,00} \\
5,00 \\
-\end{array}$ & $\begin{array}{l}13 \\
04 \\
01 \\
10 \\
\overline{0 i} \\
- \\
04\end{array}$ & $\begin{array}{r}39,40 \\
12,12 \\
3,03 \\
30,30 \\
- \\
3,03 \\
- \\
12,12\end{array}$ & $\begin{array}{l}63 \\
15 \\
10 \\
10 \\
08 \\
07 \\
05 \\
05\end{array}$ & $\begin{array}{r}51,21 \\
12,20 \\
8,13 \\
8,13 \\
6,50 \\
5,69 \\
4,07 \\
4,07\end{array}$ \\
\hline Total & 70 & 100,00 & 20 & 100,00 & 33 & 100,00 & 1231 & 100,00 \\
\hline
\end{tabular}

A análise dos dados da tabela 5 possibilita verificar que a maior proporção de causas de insatisfaç̃̃o com a assistência recebida no transoperatório, nos três hospitais, ocorreu em relação à desatenção da equipe cirúrgica para com o paciente $(51,21 \%)$.

Verifica-se também que, no hospital A, dos 70 pacientes insatisfeitos com a assistência durante o transoperatório, $09(12,86 \%)$ reclamaram das atitudes agressivas para com 0 paciente. No hospital B, dos 20 pacientes, $4(20,00 \%)$ reclamaram da desorganização no atendimento. No hospital C, dos 33 pacientes, $10(30,30 \%)$ reclamaram da fala insistente e voz. irritante de um elemento da equipe durante o transoperatorio.

Constata-se, também, que os elementos da equipe de enfermagem foram raramente mencionados pelos pacientes. Esperava-se que a(o) enfermeira(o) fosse citada(o) com mais freqüẻncia, mesmo que sob uma percepção irreal das categorias funcionais.

O baixo índice da identificação da(o) enfermeira(o), aqui referida como representante operacional da equipe de enfermagem, parece retratar a omissão da(o) enfermeira(o) do centro cirúrgico no relacionamento interpessoal com o paciente, no periodo pré e transoperatório.

- Fatores que constituem para o paciente, no contexto ambiental do centro cirúrgico, percepçōes agradáveis e percepçס̃es desagradáveis.

Procurou-se, neste trabalho, identificar, também, os insumos de natureza humana e material que constituem, segundo a percepção do paciente, os fatores mais agradáveis e os mais desagradáveis no contexto ambiental do sistema centro cirúrgico. 
A literatura tem abordado o sistema centro-cirúrgico quase sempre pelo seu efeito agressor sobre o paciente. Parece que se está, sempre, partindo da premissa de que o ambiente do centro cirúrgico é constituído somente de fatores desagradáveis.

É preciso considerar-se que nem sempre o desconhecido é de efeito apenas negativo. Por vezes, a impressão causada por novo fato ou objeto, ainda que desconhecido, pode resultar agradável ou, ainda, não ser suficientemente forte para ser registrada como importante.

Os resultados demonstram que os fatores mencionados em maior número pelos pacientes, tanto em percepçð̃es agradáveis como em percepçð̄es desagradáveis, estão relacionados à modalidade visual, com $301(47,11 \%)$ e 224 $(38,42 \%)$ dos casos, respectivamente.

Para os fatores agradáveis, a modalidade de percepção auditiva veio a seguir, citada por $203(31,77 \%)$ dos pacientes. Entretanto, para os fatores desagradáveis, a modalidade citada em segundo lugar foi a de percepção olfativa, por $131(22,47 \%)$ dos pacientes.

Além dessas percepções, direta e especificamente ligadas aos órgãos dos sentidos, buscou-se obter dados sobre "outras percepçðes" não restritas às sensações imediatamente vinculadas a esses receptores, mas, também, associadas a fatores psicológicos; săo esses fatores conceituados, para efeitos práticos, em MARX \& HILLIX ${ }^{21}$, como sendo mais do que fenômenos apenas observáveis diretamente e, sim, manifestações de natureza emociona! associadas a esses fenômenos.

Constata-se que em "outras percepçőes" agradáveis, os pacientes referiram-se, apenas, às de comportamento emocional, em relação a atitudes de relacionamento interpessoais entre equipe cirúrgica e paciente.

"Outras percepçðes" desagradáveis ocupam o 30 lugar no contexto ambiental, relatadas por 120 pacientes, sendo que $25,00 \%$ mencionaram, como a mais desagradável, a indiferença da equipe cirúrgica na assistência ao paciente. Observa-se também que $12,50 \%$ dos pacientes manifestam, como mais desagradável, a sensação perceptiva do seu próprio corpo restringido à mesa cinúrgica.

Com base no exposto, acreditamos ter obtido informaçoes de valia a serem tomadas, ao menos como ponto de partida, como subsídios para a eficiente retroalimentação do sistema centro cirúrgico.

A assistência no transoperatório deixa muito a desejar, a partir, mesmo, da assistência pré-operatória, cujo resultado, bom ou mau, é levado com o paciente ao centro cirúrgico.

O desconhecimento do que está por acontecer, ou está acontecendo, e a desatençăo por parte dos membros da equipe cirúrgica pontificaram como 
agentes causais coadjuvantes de todo um quadro de estresse, que pode ser, pelo menos minorado, com a correção de tais causas.

A falta de atuação da(o) enfermèira(o), desde o pré-operatório, eficiente e centrada na pessoa humana, é o que parece ser, entre outras, a grande falha do sistema. Vê-se que muito mais pode ser feito pelo paciente na dependência do pessoal de enfermagem, dando-se a conhecer e aproximando-se dele, explicando-lhe, tanto quanto sua compreensão possa permitir, tudo aquilo que irá encontrar, pelo que irá passar no transoperatório e, sobretudo, acompanhando-o e prestando-lhe o melhor de sua atençåo profissional e humana,

\section{CONCLUSÕES}

1- Os principais problemas sentidos pelos pacientes, em sua interação com o contexto do centro cirúrgico, durante o perfodo transoperatório, foram: desconforto físico, medo da morte, medo da anestesia e desatenção dos elementos da equipe cirúrgica.

2 - Para o paciente no transoperatorio, é quase inexpressiva a atuação da(o)) enfermeira(o) de centro cirúrgico, marcadamente porque:

2.1 A(O) enfermeira(o) nóo se dá a conhecer, como elemento individualizado da equipe cirúrgica, a partir da recep̧̧ăo e no relacionamento com o paciente durante o transoperatório;

$2.2 \mathrm{~A}(\mathrm{O})$ enfermeira(o) năo é atuante quanto às explieaçðes ao paciente sobre os cuidados de enfermagem e os procedimentos médicos durante 0 ato anestésico-cirúrgico; tampouco procura estabelecer, com o paciente, relação de afetividade, como base para uma assitência integral;

$2.3 \mathrm{~A}(\mathrm{O})$ enfermeira(o) não oferece a necessária atenção e o necessário atendimento às necessidades do paciente, manifestadas durante o período transoperatório.

3-O contex to ambiental do centro cirúrgico impressiona, nitidamente, as; percepçбes do paciente, destaeando-se alguns fatores no periodo transoperatório, considerados agradáveis ou desagradáveis.

3.1 A comunicação verbal, durante o período transoperatório, constitui fator de percepção auditiva agradável, quando relacionada a explicaçðees do ato anestésico-cirúrgico e palavras de apoio;

3.2 A forma e conteúdo do diálogo entre os elementos da equipe cirúrgica e destes com o paciente; e o ruído do equipamento cirúrgico são, predominantemente, fatores de percepçôes auditivas desagradáveis;

3.3 Os fatores que determinam percepçð̃es emocionais desagradáveis estão 
ligados ao comportamento dos elementos da equipe cirúrgica no relacionamento com o paciente e às sensações perceptivas do próprio corpo (forma de restrição sobre a mesa cirúrgica e mudanças de posição).

RODRIGUES, A. I. The patient in the surgical unit system: study about perceptions and opinions of patients relating to the transoperatory period. Rev. Esc. Enf. USP, São Paulo, 18(2):163-176, 1984.

The author made a study about the perceptions and opinions of the patient, during the period of transoperatory, in relation with the fisical human surroudings of the surgical system in three hospitals in Londrina.

\section{REFERÊNCIAS BIBLIOGRÁFICAS}

1. ANGERAMI, E. L. S. Estudo epidemiológico da temperatura corporal em pacientes internados em um hospital escola. Sťo Paulo, 1977. p. 62-5 (Tese de Livre-Docência - Escola de Enfermagem de Ribeirão Preto da USP).

2. ARMSTRONG, D. M. Nursing administrator's expectations of leader. AORN J., Denver, 25: 859. -64, Apr. 1977.

3. BARNETT, L. A. Preparing your patient for the operating room. AORN J., Denver, 18:534-39, Sept. 1973.

4. BELAND, I. L. \& PASSOS, J. Y. Enfermagem clínica: aspectos fisiológicos e psicossociais São Paulo, EPU, 1978. v. 1, 446 p.

5. BERRY, D. M. \& MICHAEL, M. G. Professional nurse on the operating room team. AORN J., Denver, 11:41-4, Feb. 1970.

6. BRUNNER, L. S.; EMERSON, C. P.; FERGUSON, L. K.; SUDDART, D. S. Enfermería médico-quirúrgica. 2.ed. México, Interamericana, 1971. p. 30-2;103-20;1064-74.

7. CASTELLANOS, B. E. P. Necessidade humana básica "Liberdade". Enf. Novas Dimens, São Paulo, 4:245-253, set./out. 1978.

8. CASTELLANOS, B. E. P.; JOUCLAS, V. M. G.; SALZANO, S. D. T. Centro cirúrgico: subsistema do macrosistema hospital. Enf. Novas Dimens, São Paulo, 1:126-29, jul./ago. 1975.

9. CHAVES, M. Saúde e sistemas. Rio de Janeiro, Fundação Getúlio Vargas, 1972. 212 p.

10. De LAPPE, A. Shhh! "Sleeping”' OR patients are listening. AORN J., Denver, 19:1334-48, June 1974.

11. Du GAS, B. W. Enfermagem prática. 3.ed. Rio de Janeiro Interamericana, 1977. p. 166-74.

12. EPSTEIN, C. Interação ef etiva na enfermagem. Săo Paulo, E. P. U., 1977. 173 p.

13. FAY, M. R. Nursing process in the recovery room. AORN J., Denver, 24:1069-75, Dec. 1976.

14. FEHLAU, M. T. Applying the nursing process to patient care in the operating room. Nurs Clin North Amer., Philadelphia, 10:617-623, Dec. 1975.

15. GRAHAM, L. E. \& CONLEY, E. M. Evaluation of anxiety and fear in adult surgical patients. Nurs. Res, New York, 20:113-22, Mar./Apr. 1971.

16. JOUCLAS, V. M. G. Elaboraçăo e avaliaç̧̃o de um instrumento de comunicaçăo que favoreça a assistência de enfermagem no transoperatório. Såo Paulo, 1977. (Dissertação de Mestrado Escola de Enfermagem da USP).

17. LAMBERTSEN, E. C. Equipe de enfermagem organizaçăo e funcionamento. Rio de Janeiro, ABEn, 1966.p.15-18.

18. LAUFMAN, H. What's wrong with our operating rooms? Amer. J. Surg, New York, 122:33243, Sept. 1971. 
19. McPHAIL, J. A plea for profissional nurse in the OR. AORN J., Denver, 19:872-6, Apr. 1974.

20. MAHOMET, A. D. Nursing diagnosis for the OR nurse. AORN J., Denver, 22:709, Nov. 1975.

21. MARX, M. H. \& HILLX, W. A Sistemas e teorias em psicologia 3.ed. Stro Paulo, Cultrix, 1973. p. 427-36.

22. NOLAN, M. Team nursing in the OR. Amex. J. Nurs, New York, 74:272-4, Feb. 1974.

23. OLSEN, M. OR murse's perception of strew. AORN J., Denver, 25:43-8, Jan. 1977.

24. PANZA, A. M. M. Efeito de visita próoperatoria da enfermeira do centro cinírico sobre os estrease do paciente no pá-operatório no die da cirurgin e no pór-operatório. Ś̃o Paulo, 1977. (Dissertacio de Mestrado - Escoli de Enfermagem da USP).

25. RADINA, B. What the operatine room aurse wants to know. AORN J., Denver, 10:39, Aug. 1969.

26. RICHTER, E. O paciente como centro ma sala de operą̧⿸丆es. Rev. Fuil Fosp., Sáo Paulo, 9:20, abr. 1961.

27. WELSH, J. \& RKCHARDSON, A. How well do you know your patient nurse? NAT News, Windsor, 13(5):12-15, july 1976.

28. YANICK, M \& MODOBNIKAR, N. S. Don't you miss patient care? Amer. J. Nurk, New York, 67:1260-2, Jane 1967. 